\title{
BIBECHANA
}

ISSN 2091-0762 (Print), 2382-5340 (Online)

Journal homepage: http://nepjol.info/index.php/BIBECHANA

Publisher: Department of Physics, Mahendra Morang A.M. Campus, TU, Biratnagar, Nepal

\section{Investigation on thermo-physical properties of liquid In-Tl alloy}

\author{
I. B. Bhandari ${ }^{1,2}$, N. Panthi ${ }^{1,3}$, I. Koirala ${ }^{1 *}$ \\ ${ }^{1}$ Central Department of Physics, Tribhuvan University, Kirtipur, Nepal \\ ${ }^{2}$ Department of Applied Sciences, Purwanchal Campus, Tribhuvan University, Dharan, Nepal \\ ${ }^{3}$ Department of Physics, Patan Multiple Campus, Tribhuvan University, Lalitpur, Nepal \\ *E-mail: ikphysicstu@gmail.com
}

\section{Article Information:}

Received: June 29, 2020

Accepted: August 8, 2020

Keywords:

Mixing properties

Ordering energy

Complex formation model

Segregation

\begin{abstract}
This research explores mixing behaviour of liquid In - Tl system through thermodynamic and the structural properties on the basis of Complex Formation Model. The properties like surface tension and viscosity have been analyzed through simple statistical model and Moelwyn - Hughes equation. The interaction parameters are found to be positive, concentration independent and temperature dependent. Theoretical results are in a good agreement with the corresponding literature data which support homo-coordinating tendency in the liquid In-Tl alloy.
\end{abstract}

DOI: https://doi.org/10.3126/bibechana.v18i1.29531

This work is licensed under the Creative Commons CC BY-NC License. https://creativecommons.org/licenses/by-nc/4.0/

\section{Introduction}

Indium is a substance which is used in solder alloys which are applied in electronics for assembling semiconductor chips to a base and hybrid integrated circuits and to seal glass to metal in vacuum tubes. Fusible indium alloys are used to bend thin walled tubes without wrinkling the wall or changing the original cross-section. These alloys are not only used in fire control system, restraining links that hold alarm, water valve and door operating mechanism but also used as temperature indicators in situations where other methods of temperature measurements are impracticable and infeasible [1].
Indium is also used in nuclear reactor control rod alloys, low pressure sodium lamps and alkaline batteries. Additions of indium to lead-tin bearings are utilized in piston type aircraft engines, high performance automobile engines and in turbodiesel truck engines. The addition of indium to gold dental alloys recuperates their mechanical properties and increases resistance to discoloring. Small amount of indium is used to improve the machinability of gold alloys for jewelry [1].The indium-thallium alloy is a classic type of shape memory alloy with a low melting temperature. It has wide range of practical applications in the field of metallurgy which includes the use in 
thermostats, hydraulic lines and electrical circuits [2]. Thallium alone is improper for direct use because of its properties of toxicity, unfavorable mechanical properties and significant tendency to oxidize. Thallium contains the most constant atomic vibration so far experimented. This property of $\mathrm{Tl}$ preceded it to be used in atomic clocks. Thallium immediately forms alloys with most other metals. There is incomplete mutual insolubility with iron and limited solubility in the liquid state with copper, aluminum, zinc, arsenic, manganese and nickel. Gold, silver, cadmium and tin formulate simple eutectic point with thallium. Thallium also forms binary alloys with antimony, barium, calcium, cerium, cobalt, germanium, lanthanum, lithium, magnesium, strontium, tellurium, bismuth and indium. The ternary alloys of thallium $\mathrm{Tl}-\mathrm{Pb}$ $\mathrm{Bi}, \mathrm{Tl}-\mathrm{Al}-\mathrm{Ag}$, In-Hg-Tl, Sn-Cd-Tl, Bi-Sn-Tl and $\mathrm{Bi}-\mathrm{Cd}-\mathrm{Tl}$ are used as semiconductors in ceramic compounds. Thallium has good wear resistance when it is used in bearing shafts. Thallium containing alloys are frequently recommended for bearings, electronics industry such as in solid state rectifiers, electrical fuses and soldering materials [1]. The study of In-Tl alloy is also useful to investigate the corresponding higher order alloy through different approaches [3]. There is difficulty in studying the properties of alloys in liquid state due to lack of long range atomic order. Therefore, theoreticians have exercised different models to understand the properties of various binary liquid alloys [4-22]. The different properties were studied at fixed temperature of $723 \mathrm{~K}$ through different models. In present work, we have explored the energetic of $\mathrm{In}-\mathrm{Tl}$ alloy at a temperature of $723 \mathrm{~K}$ using complex formation model [23]. The outcomes are analyzed and compared with literature data [24] to explicate the accuracy of this method in thermodynamic and structural description of the presented binary system.

\section{Theory}

\section{Thermodynamic properties}

If a binary alloy contains $\mathrm{N}_{\mathrm{A}}=\mathrm{x}$ number of $\mathrm{A}$ atoms and $\mathrm{N}_{\mathrm{B}}=(1-\mathrm{x})$ number of $\mathrm{B}$ atoms, so that total number of atoms is $\mathrm{N}=\mathrm{N}_{\mathrm{A}}+\mathrm{N}_{\mathrm{B}}$. When components $\mathrm{A}$ and $\mathrm{B}$ are amalgamated together to form a binary A-B solution, thermodynamic properties are changed. The liquid alloy is considered to be ternary mixture of three species; A atom, $B$ atom and chemical complex $A_{u} B_{v}$, is also called conformal solution. The number of free atoms will be reduced due to compound formation in the melt. Now for $n_{1} g$ atoms of $A, n_{2} g$ atoms of $\mathrm{B}$ and $\mathrm{n}_{3} \mathrm{~g}$ atoms of $\mathrm{A}_{\mathrm{u}} \mathrm{B}_{\mathrm{v}}$,

$n_{1}=x-u n_{3}$ and $n_{2}=(1-x)-v n_{3}$

The total number of atoms after mixing can be given as

$n=n_{1}+n_{2}+n_{3}=1-(u+v-1) n_{3}$

The free energy of mixing of the binary A-B mixture can be written as [23],

$G_{M}=-n_{3} g+G^{\prime}$

Here, $-n_{3} g$ stands for lowering of free energy due to compound formation, $\mathrm{g}$ is the formation energy of complex. $G^{\prime}$ is the free energy of mixing of the ternary mixture of $\mathrm{A}, \mathrm{B}$ and $\mathrm{A}_{\mathrm{u}} \mathrm{B}_{\mathrm{v}}$. If the ternary mixture is an ideal solution,

$G^{\prime}=R T \sum n_{i} \ln \left(\frac{n_{i}}{n}\right)$

If the effects of differences in sizes of the various constituents in the mixture cannot be ignored and the interaction $\omega_{i j}$ are small but not zero, the theory of regular solutions in the zeroth approximation [25] or the conformal solution approximation [26] is valid. For regular solution

$G^{\prime}=R T \sum n_{i} \ln \left(\frac{n_{i}}{n}\right)+\sum \omega_{i j}\left(\frac{n_{i} n_{j}}{n}\right)$

This equation is concerned to conformal solution approximation. Where $\omega_{i j}=0$ (for $\mathrm{i}=\mathrm{j}$ ) are termed as the interaction energies and by definition are independent of concentration, although they are depended upon temperature and pressure.

Now the expression for free energy of mixing $G_{M}$ for the compound forming binary alloy is

$G_{M}=-n_{3} g+R T \sum_{i=1}^{3} n_{i} \ln \left(\frac{n_{i}}{n}\right)+$

$\sum \sum_{i<j}\left(\frac{n_{i} n_{i}}{n}\right) \omega_{i j}$ 
The expression for heat of mixing $\mathrm{H}_{M}$ is given by[23]

$H_{M}=G_{M}-T\left(\frac{\partial G_{M}}{\partial T}\right)_{P}$

Substituting for $\mathrm{G}_{\mathrm{M}}$,

$$
\begin{aligned}
H_{M}=-n_{3} g+ & R T \sum_{1}^{3} n_{i} \ln \left(\frac{n_{i}}{n}\right) \\
& +\sum_{i<j} \sum\left(\frac{n_{i} n_{j}}{n}\right) \omega_{i j} \\
& -T \frac{\partial}{\partial T}\left[-n_{3} g+R T \sum_{i=1}^{3} n_{i} \ln \left(\frac{n_{i}}{n}\right)\right. \\
& \left.+\sum_{i<j} \sum\left(\frac{n_{i} n_{j}}{n}\right) \omega_{i j}\right] \\
H_{M}=-n_{3}[g- & \left.T\left(\frac{\partial g}{\partial T}\right)_{P}\right]+\frac{1}{n} \sum_{i<j} \sum\left(n_{i} n_{j}\right)\left[\omega_{i j}-\right. \\
\left.T\left(\frac{\partial \omega_{i j}}{\partial T}\right)_{P}\right] &
\end{aligned}
$$

The expression for entropy of mixing $\mathrm{S}_{\mathrm{M}}$ can be obtained as [23]

$S_{M}=n_{3} \frac{\partial g}{\partial T}-R \sum_{i=1}^{3} n_{i} \ln \frac{n_{i}}{n}-\sum_{i<j} \sum \frac{n_{i} n_{j}}{n} \frac{\partial \omega_{i j}}{\partial T}$

The equilibrium value of $n_{3}$ at a given pressure and temperature is given by[23]

$\left(\frac{\partial G_{M}}{\partial n_{3}}\right)_{T, P, N, C}=0$

Substituting the value of $\mathrm{G}_{\mathrm{M}}$ from Equation (6) and after some algebraic calculation

$\ln \left(n_{3} n^{u+v-1} n_{1}^{-u} n_{2}^{-v}\right)+Y=\frac{g}{R T}$

The Equation (11) is called equilibrium equation, where

$$
\begin{gathered}
Y=\left[\frac{n_{1} n_{2}}{n^{2}}(u+v-1)-u \frac{n_{2}}{n}-v \frac{n_{1}}{n}\right] \frac{\omega_{12}}{R T}+ \\
{\left[\frac{n_{2} n_{3}}{n^{2}}(u+v-1)-v \frac{n_{3}}{n}+\frac{n_{2}}{n}\right] \frac{\omega_{23}}{R T}+} \\
{\left[\frac{n_{1} n_{3}}{n^{2}}(u+v-1)-u \frac{n_{3}}{n}+\frac{n_{1}}{n}\right] \frac{\omega_{13}}{R T}}
\end{gathered}
$$

\section{Structural Properties}

The concentration fluctuation at long wavelength limit is of good interest because any deviation from ideal value $S_{c c}^{i d}(0)$ is significant in describing the nature of ordering and phase segregation in molten alloys. This has been used to investigate the nature of atomic order. The concentration fluctuation at long wavelength limit is related with free energy of mixing by the expression [27],

$$
\begin{aligned}
& S_{C c}(0)=\frac{R T}{\frac{\partial^{2} G_{M}}{\partial c^{2}}} \\
& S_{C c}(0)=\frac{R T}{R T \sum_{i=1}^{3}\left(\frac{\left(n_{i}^{\prime}\right)^{2}}{n_{i}}-\frac{\left(n^{\prime}\right)^{2}}{n}\right)+2 n \sum_{i<j} \sum \omega_{i j}\left(\frac{n_{i}}{n}\right)^{\prime}\left(\frac{n_{j}}{n}\right)^{\prime}}
\end{aligned}
$$

Theoretically computed values of $S_{c c}(0)$ can be compared with the observed values computed from activity data by the expression,

$$
S_{c c}(0)=(1-x) a_{A}\left(\frac{\partial a_{A}}{\partial c}\right)_{T, P, N}^{-1}=x a_{B}\left(\frac{\partial a_{B}}{\partial c}\right)_{T, P, N}^{-1}
$$

The ideal value of $\mathrm{S}_{\mathrm{cc}}(0)$ can be expressed as, $S_{c c}^{i d}(0)=x(1-x)$

The Warren-Cowley short range order parameter quantify the degree of local order in the binary alloy [28,29]. The theoretical values of this parameter can be calculated as

$\alpha_{1}=\frac{(s-1)}{s(z-1)+1}, S=\frac{s_{c c}(0)}{S_{c c}^{i d}(0)}$

where $\mathrm{z}$ is coordination number, which is taken as 10 for our calculation.

\section{Transport Properties}

The mixing behaviour of the alloys forming molten alloy can also be studied at the microscopic level in terms of coefficient of diffusion. The mutual diffusion coefficient $\left(\mathrm{D}_{\mathrm{M}}\right)$ of binary liquid alloys can be expressed in terms of activity $\left(a_{i}\right)$ and selfdiffusion coefficient $\left(D_{\text {id }}\right)$ of pure component with the help of Darken's equation [30]

$D_{M}=D_{i d} x \frac{d \ln a_{i}}{d x}$

with $D_{M}=c_{A} D_{B}+c_{B} D_{A}$

where $\mathrm{D}_{\mathrm{A}}$ and $\mathrm{D}_{\mathrm{B}}$ are the self - diffusion

coefficients of pure components $\mathrm{A}$ and $\mathrm{B}$

respectively,

The expression for $D_{M}$ in terms of $S_{c c}(0)$ can be given as

$\frac{D_{M}}{D_{i d}}=\frac{S_{c c}^{i d}(0)}{S_{c c}(0)}$ 
The mixing behaviour of liquid alloys at microscopic level can also be understood in terms of viscosity. The Moelwyn - Hughes equation for viscosity of liquid alloy [31] is

$\eta=\eta_{i d}\left[1-x_{A} x_{B}\left(\frac{2 g}{R T}\right)\right]$

with

$\eta_{i d}=x \eta_{A}+(1-x) \eta_{B}$

where $\eta_{i}$ is the viscosity of pure component i. At

temperature $\mathrm{T}$, it is given by [32]

$\eta_{i}=\eta_{i 0} \exp \left(\frac{E}{R T}\right)$

Here $\eta_{i 0}$ a constant in the unit of viscosity and $\mathrm{E}$ is the activation energy.

\section{Surface Properties}

The surface properties of the liquid mixture give insight into the metallurgical phenomenon, such as crystal growth, wielding, gas absorption and nucleation of gas bubbles [33]. The expressions for surface tension proposed by Prasad et al., [34,35], has been reduced in the simple form using zeroth approximation as

$\tau=\tau_{A}+\frac{k_{B} T}{\xi} \ln \frac{x^{s}}{x}+\frac{g}{\xi}\left[p\left(1-x^{s}\right)^{2}+\right.$

$\left.(q-1)(1-x)^{2}\right]$

$\tau=\tau_{B}+\frac{k_{B} T}{\xi} \ln \frac{\left(1-x^{s}\right)}{(1-x)}+\frac{g}{\xi}\left[p\left(x^{s}\right)^{2}+(q-1)(x)^{2}\right]$

where $\tau_{A}$ and $\tau_{B}$ are the surface tensions of pure components $\mathrm{A}$ and $\mathrm{B}$ respectively, $x$ and $x^{S}$ are the bulk and surface concentration of the components of alloy, $\mathrm{p}$ and $\mathrm{q}$ are called coordination fractions, which are defined as the fraction of the total number of nearest neighbors made by atom within its own layer and that in the adjoining layer. The coordination fractions $\mathrm{p}$ and $\mathrm{q}$ are related to each other by the relation

$p+2 q=1$, for closed packed structure, $p=0.5$ and $q=0.25$

The expression for the mean atomic surface area $\xi$ is

$\xi=\sum c_{i} \xi_{i}$

The atomic surface are for each component is
$\xi_{i}=1.102\left(\frac{\Omega_{i}}{N_{A}}\right)^{2 / 3}$

where $\Omega_{i}$ is the molar volume of the component $i$ and $N_{A}$ represents Avogadro number. Equating equations (22) and (23), we can solve it for $x^{S}$ as the function of $x$ and hence compositional dependence of surface tension can be evaluated.

where $\tau_{A}$ and $\tau_{B}$ are the surface tensions of pure components $\mathrm{A}$ and $\mathrm{B}$ respectively, $x$ and $x^{S}$ are the bulk and surface concentration of the components of alloy, $\mathrm{p}$ and $\mathrm{q}$ are called coordination fractions, which are defined as the fraction of the total number of nearest neighbors made by atom within its own layer and that in the adjoining layer. The coordination fractions $\mathrm{p}$ and $\mathrm{q}$ are related to each other by the relation

$p+2 q=1$, for closed packed structure, $p=0.5$

and $q=0.25$

The expression for the mean atomic surface area $\xi$ is

$\xi=\sum c_{i} \xi_{i}$

The atomic surface are for each component is

$\xi_{i}=1.102\left(\frac{\Omega_{i}}{N_{A}}\right)^{2 / 3}$

where $\Omega_{i}$ is the molar volume of the component $\mathrm{i}$ and $N_{A}$ represents Avogadro number. Equating equations (22) and (23), we can solve it for $x^{s}$ as the function of $\mathrm{x}$ and hence compositional dependence of surface tension can be evaluated.

\section{Results and Discussion}

\section{Thermodynamic properties}

The experimental data on the thermodynamic properties as well as phase diagram information [24] have been used for the calculation of order energy parameters for liquid phase In-Tl system. The data set of the Gibbs energy of mixing $\left(\mathrm{G}_{\mathrm{M}}\right)$ were taken as input data to calculate by the CFM the interaction energy parameters, i.e. $\mathrm{g}, \omega_{12}, \omega_{13}$, $\omega_{23}$. The starting values of $\mathrm{g} / \mathrm{RT}$ and $\omega_{\mathrm{ij}} / \mathrm{RT}$ were obtained as suggested in ref. [23]. Equilibrium Equation (11) along with Equations (1) and (2) were applied to compute the number of complexes, 
$\mathrm{n}_{3}$, as a function of concentration. The values of interaction energy parameters were adjusted to give the concentration dependence of free energy of mixing which fits well with the corresponding thermodynamic data. From the phase diagram [24] In-Tl alloy is expected to aggregate with stoichiometry In-Tl ( $\mathrm{u}=1, \mathrm{v}=1)$. The calculations were done at temperature of $723 \mathrm{~K}$. The interaction energy parameters for In-Tl liquid alloys are found to be $\mathrm{g}=0.755 \mathrm{RT}, \omega_{12}=0.476 \mathrm{RT}, \omega_{13}=1.610 \mathrm{RT}$ and $\omega_{23}=1.481 \mathrm{RT}$. The positive interaction energies imply the repulsion between the corresponding species.

The concentration dependence of the equilibrium values of chemical complexes, $\mathrm{n}_{3}$, (Fig. 1) displays the symmetry with the maximum value of 0.4178 at equiatomic composition. The curve describing the Gibbs free energy of mixing of the In-Tl liquid phase is symmetric with respect to the equiatomic composition (Fig. 2). Theoretical calculation of free energy of mixing for In-Tl liquid alloy shows that In - Tl alloy in liquid state is weakly interacting or homo-coordinating system. There is an excellent agreement between the experimental and calculated integral free energies. Very poor agreement of calculated values of $\mathrm{H}_{M}$ and $\mathrm{S}_{M}$ with experimental simply indicates the importance of the dependence of interaction energies on temperature. To account this, we have used Equations (8) and (9) to determine the variation in energy parameters with respect to temperature from experimental values of $\mathrm{H}_{M}$ and $\mathrm{S}_{M}$ [24]. The temperature dependent interaction energies at $\mathrm{T}=723 \mathrm{~K}$ are found to be

$$
\begin{aligned}
& \frac{1}{R} \frac{\partial g}{\partial t}=0.845, \frac{1}{R} \frac{\partial \omega_{12}}{\partial t}=0.383, \\
& \frac{1}{R} \frac{\partial \omega_{13}}{\partial t}=1.493, \\
& \frac{1}{R} \frac{\partial \omega_{23}}{\partial t}=1.430
\end{aligned}
$$

It is found from the present analysis that the heat of mixing and entropy of mixing both are positive at all concentrations. Our theoretical calculation shows that the maximum value of the heat of mixing is $0.0512 \mathrm{RT}$ at $\mathrm{x}_{\mathrm{In}}=0.6$ (Fig.3) and the maximum value of entropy of mixing is 0.6107 at $\mathrm{x}_{\mathrm{In}}=0.5$ (Fig.4). There is excellent agreement between experimental and calculated values of $\mathrm{H}_{\mathrm{M}}$. The calculated values of $S_{M}$ deviates from experimental values by maximum percentage of 8.31 at $\mathrm{x}_{\mathrm{In}}=0.8$ and by minimum percentage of 5.56 at $\mathrm{x}_{\mathrm{In}}=0.4$. This deviation is because of the propagation of error from previous calculation.

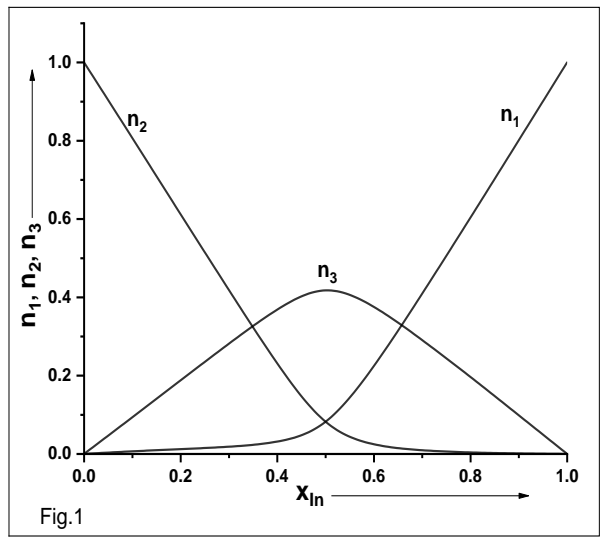

Fig.1: Number of complexes $\left(\mathrm{n}_{1}, \mathrm{n}_{2}, \mathrm{n}_{3}\right)$ vs. concentration $\mathrm{x}_{\mathrm{In}}$ of liquid $\mathrm{In}-\mathrm{Tl}$ alloy at $723 \mathrm{~K}$.

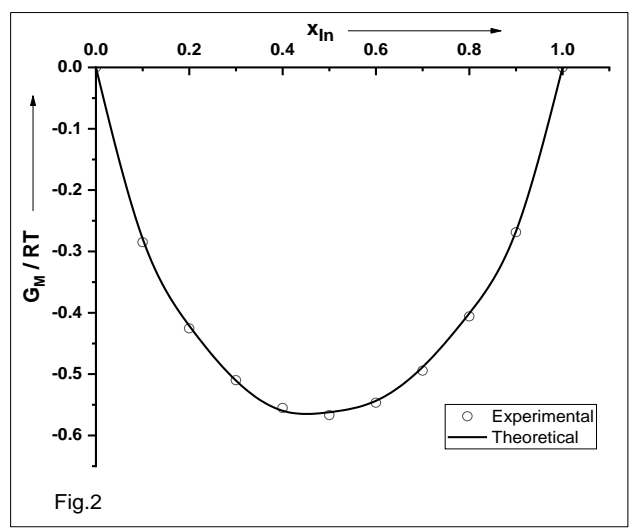

Fig. 2: Free energy of mixing $\left(\mathrm{G}_{\mathrm{M}} / \mathrm{RT}\right)$ vs. concentration $\left(\mathrm{x}_{\text {In }}\right)$ of liquid $\mathrm{In}-\mathrm{Tl}$ alloy at $723 \mathrm{~K}$.

\section{Structural Properties}

It has been reported that when $\mathrm{S}_{\mathrm{cc}}(0)<\mathrm{S}_{\mathrm{cc}}^{\mathrm{id}}(0)$, the existence of chemical ordering leading to complex 
formation is expected while $S_{c c}(0)>S_{c c}^{i d}(0)$, is an indication of segregation. The same interaction parameters used in the calculation of the thermodynamic properties were employed in the calculations of $S_{\mathrm{cc}}(0)$ using Equation (14) while the experimental values of $\mathrm{S}_{\mathrm{cc}}(0)$ were obtained from Equation (15) using the experimental activity data. The results obtained from the above computations are plotted in Fig. (5). It is found that $S_{c c}(0)>$ $S_{\mathrm{cc}}^{\text {id }}(0)$ throughout the entire concentration range, this also confirms the presence of chemical segregation or a preference for like atoms to pair. The value of short range order parameter is positive through the whole concentration range which indicates that the alloy is segregating at all compositions. The value of short range order parameter has been found maximum $(=0.02438)$ at $\mathrm{x}_{\mathrm{In}}=0.5$ at $723 \quad \mathrm{~K} \quad$ (Fig. (6))

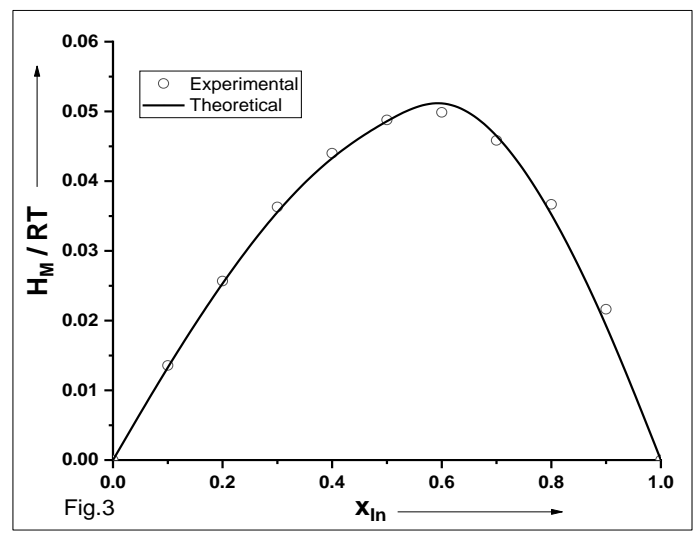

Fig. 3: Heat of mixing $\left(\mathrm{H}_{\mathrm{M}}\right)$ vs. concentration of indium $\left(\mathrm{x}_{\mathrm{In}}\right)$ in the liquid $\mathrm{In}-\mathrm{Tl}$ alloy at $723 \mathrm{~K}$.

\section{Transport Properties}

The calculated values of $\left.S_{\mathrm{cc}}(0)\right)$ by Equation (17) can be applied to evaluate the ratio of the mutual and intrinsic-diffusion coefficients $\left(\mathrm{D}_{\mathrm{M}} / \mathrm{D}_{\mathrm{id}}\right)$ using Equation (19), against the concentration of indium. We note that the ratio of diffusivities can also be used to indicate levels of order in the liquid binary alloys. The presence of chemical order is indicated by $D_{M} / D_{\text {id }}>1$. Similarly, $D_{M} / D_{\text {id }}<1$ suggests the tendency for segregation. Fig. (7) shows the plots
$D_{M} / D_{i d}$ against concentration of indium. It can be observed that the ratio $D_{M} / D_{\text {id }}$ is less than 1 throughout the whole concentration range. This indicates the homo - coordinating tendency in In$\mathrm{Tl}$ alloys at the temperature of investigation. It is also noticed that $D_{M} / D_{\text {id }}$ exhibits maximum peak at around the equi-atomic composition. The result predicted by $D_{M} / D_{\text {id }}$ is in agreement with the results obtained from the free energy of mixing, concentration fluctuations and CSRO parameter.

The viscosity of the In-Tl liquid alloy has been calculated numerically using Equation (20). From the plot of $\eta$ verses bulk concentration of indium (Fig. 8) small negative deviation from the linear law (Raoult's law) in viscosity isotherms $\eta(x)$ has been inspected.

\section{Surface Properties}

The surface concentrations and surface tension of In-Tl alloy have been computed numerically using Equations (22) and (23). The values of densities and surface tension at melting temperature $\left(\mathrm{T}^{0}\right)$ of pure atoms are taken from ref. [32]. These values have been optimized at required temperature $(\mathrm{T})$ by using the expressions

$\rho_{i}(T)=\rho_{i}^{0}+\left(T-T_{i}^{0}\right) d \rho_{i} / d t$

$\tau_{i}(T)=\tau_{i}^{0}+\left(T-T_{i}^{0}\right) d \tau_{i} / d t$

where $d \rho_{i} / d t$ and $d \tau_{i} / d t$ represent temperature coefficients of density and surface tension respectively for the components of the metal alloys. The computed values of surface concentration for molten In-Tl alloys at $723 \mathrm{~K}$ are depicted in Fig. (9). Surface concentration of indium in In-Tl alloys is found to increase with the increase of bulk concentration of In. The computed surface tension for $\mathrm{In}-\mathrm{Tl}$ alloys at $723 \mathrm{~K}$ is less than ideal values at all concentrations of indium; i.e., there is negative departure of surface tension from ideality $(\tau=$ $\tau_{\mathrm{A}} \mathrm{X}+\tau_{\mathrm{B}}(1-\mathrm{x})$ ) throughout the bulk concentrations of indium in In-Tl alloys (Fig. 10). For the In-Tl melt, the surface tension of $\mathrm{Tl}$ is smaller than that of In atom. Therefore, $\mathrm{Tl}$ atoms having lower surface tension segregates on the surface phase but In 
atoms remains in the bulk phase throughout the entire composition.

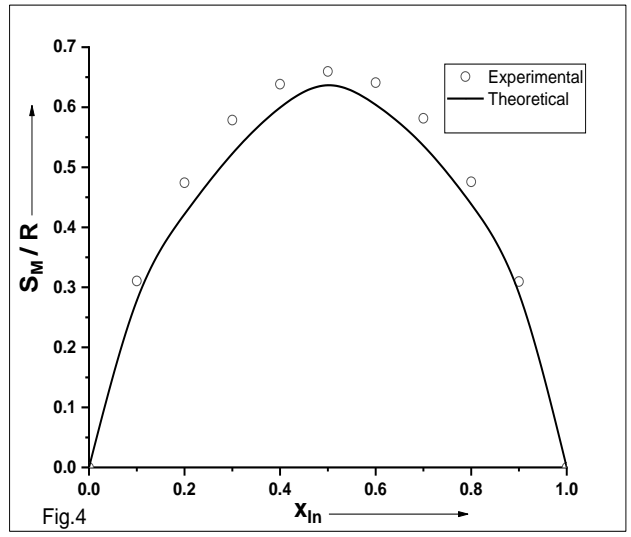

Fig. 4: Entropy of mixing $\left(\mathrm{S}_{\mathrm{M}}\right)$ vs. concentration of indium $\left(\mathrm{x}_{\mathrm{In}}\right)$ in the liquid $\mathrm{In}-\mathrm{Tl}$ alloy at $723 \mathrm{~K}$.

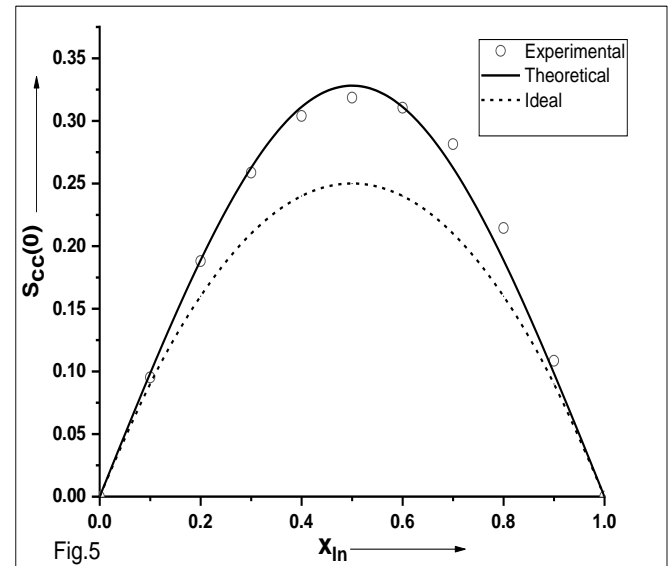

Fig. 5: Concentration fluctuation at long wavelength limit $\left(\mathrm{S}_{\mathrm{cc}}(0)\right)$ vs. concentration of indium $\left(\mathrm{x}_{\mathrm{In}}\right)$ in the liquid $\mathrm{In}-\mathrm{Tl}$ alloy at $723 \mathrm{~K}$.

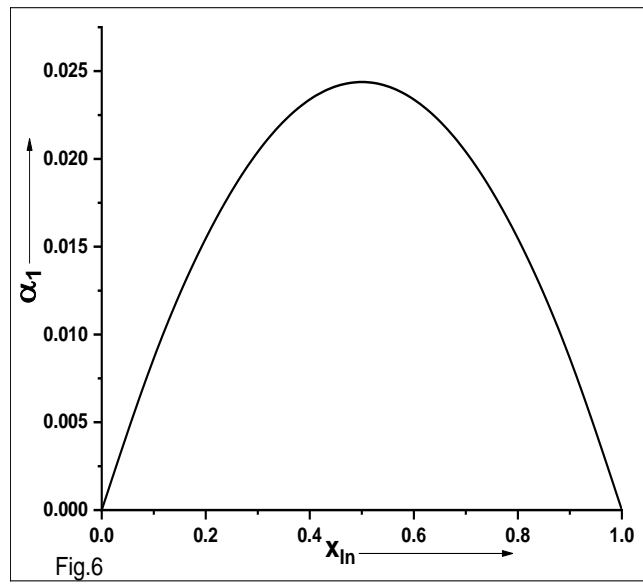

Fig. 6: Chemical short range order $\left(\alpha_{1}\right)$ vs. concentration of indium $\left(\mathrm{x}_{\mathrm{In}}\right)$ in the liquid $\mathrm{In}-\mathrm{Tl}$ alloy at $723 \mathrm{~K}$.

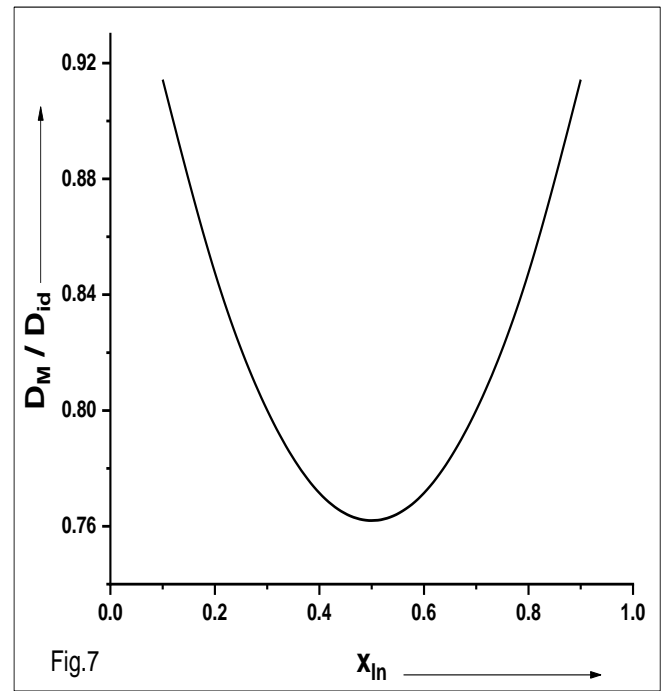

Fig. 7: Ratio of mutual and intrinsic diffusion coefficients $\left(\mathrm{D}_{\mathrm{M}} / \mathrm{D}_{\mathrm{id}}\right)$ vs. concentration of indium $\left(\mathrm{x}_{\mathrm{In}}\right)$ in the liquid $\mathrm{In}-\mathrm{Tl}$ alloy at $723 \mathrm{~K}$. 


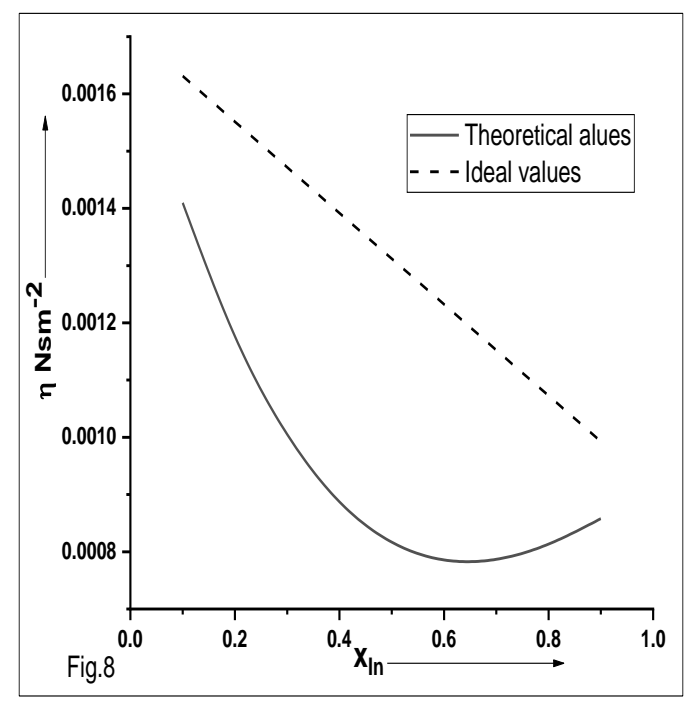

Fig. 8: Viscosity ( $\eta$ ) vs. concentration of indium $\left(\mathrm{x}_{\mathrm{In}}\right)$ in the liquid $\mathrm{In}-\mathrm{Tl}$ alloy at $723 \mathrm{~K}$.

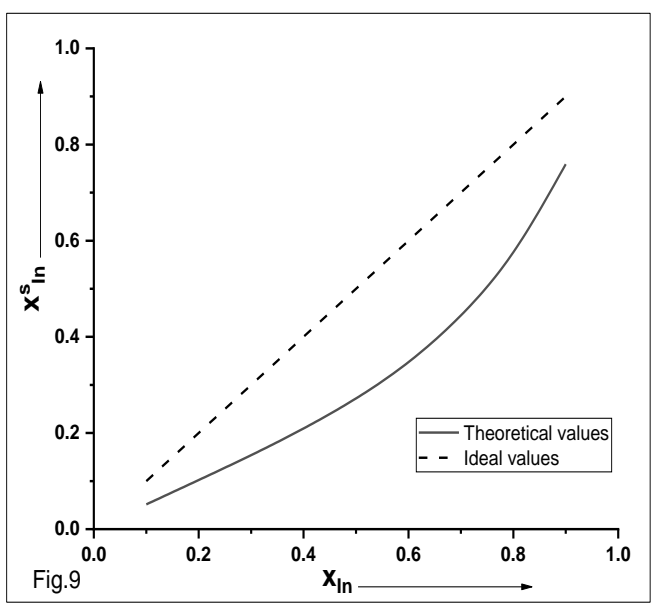

Fig. 9: Surface concentration of indium $\left(\mathrm{x}_{\mathrm{In}}^{\mathrm{S}}\right)$ vs. bulk concentration of indium $\left(\mathrm{x}_{\mathrm{In}}\right)$ in the liquid $\mathrm{In}$ $\mathrm{Tl}$ alloy at $723 \mathrm{~K}$.

\section{Conclusions}

The theoretical analysis of the thermodynamic properties reveals that there is a tendency of like atom pairing in the liquid $\mathrm{In}-\mathrm{Tl}$ alloys at all concentrations. The ordering energy is found to be positive and temperature dependent. The study of concentration fluctuation in long wavelength limit and CSRO show that there is tendency of phase separation in In - Tl liquid alloy. Negative deviation of viscosity isotherms from Raoult law is observed. Viscosity of the alloys decreases with increase in the concentrations of indium. The ratio of diffusion coefficients $\left(D_{M} / D_{\text {id }}\right)$ is found to be greater than one at all compositions which also indicates segregating tendency of the system. At the temperature of investigation, the surface tension increases with the increase in the bulk concentration of In. The surface tension of the liquid In-Tl alloy is found to be smaller than ideal values.

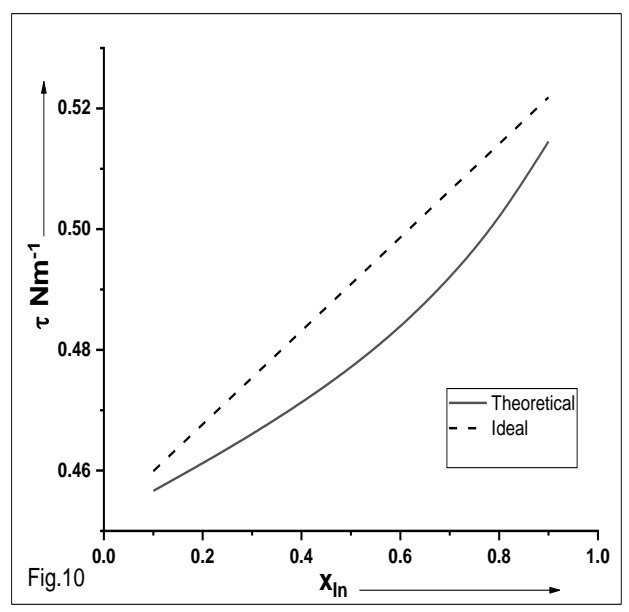

Fig. 10: Surface tension $(\tau)$ vs. bulk concentration of indium $\left(\mathrm{x}_{\mathrm{In}}\right)$ in the liquid $\mathrm{In}-\mathrm{Tl}$ alloy at $723 \mathrm{~K}$.

\section{References}

[1] F. Habashi, ed., Alloys Preparation, Properties, Applications, First, Wiley-VCH (1998).

[2] Z.P. Luo, An Overview on the Indium-Thallium (In-Tl) Shape Memory Alloy Nanowires, Metallogr. Microstruct. Anal. 1 (2012) 320. https://doi.org/10.1007/s13632-012-0046-4

[3] U. Mehta, S.K. Yadav, I. Koirala, D. Adhikari, Thermo-physical properties of ternary $\mathrm{Al}-\mathrm{Cu}-\mathrm{Fe}$ alloy in liquid state, Philos. Mag. 0 (2020) 1. https://doi.org/10.1080/14786435.2020.1775907

[4] D. Adhikari, A Theoretical study of thermodynamic properties of Cd-Bi liquid alloy, BIBECHANA 8 (2012) 90. 
https://doi.org/10.3126/bibechana.v8i0.5693

[5] D. Adhikari, I.S. Jha, B.P. Singh, J. Kumar, Thermodynamic and structural investigations of liquid magnesium - thallium alloys, J. Mol. Struct. 985 (2011)

https://doi.org/10.1016/j.molstruc.2010.10.026

[6] S. Lele, P. Ramachandrarao, Estimation of complex concentration in a regular associated solution, Metall. Trans. B 12 (1981) 659. https://doi.org/10.1007/BF02654134

[7] R. Novakovic, Thermodynamics, surface properties and microscopic functions of liquid $\mathrm{Al}$ $-\mathrm{Nb}$ and $\mathrm{Nb}-\mathrm{Ti}$ alloys, J. Non. Cryst. Solids. 356 (2010)1593.

https://doi.org/10.1016/j.jnoncrysol.2010.05.055

[8] R. Novakovic, D. Giuranno, E. Ricci, T. Lanata, Surface and transport properties of In - Sn liquid alloys, Surf. Sci. $602 \quad$ (2008) 1957. https://doi.org/10.1016/j.susc.2008.03.033

[9] Y.A. Odusote, Bulk and dynamic properties in $\mathrm{Al}-$ $\mathrm{Zn}$ and $\mathrm{Bi}$ - In liquid alloys using a theoretical model, J. Non. Cryst. Solids. 353 (2007) 1167. https://doi.org/10.1016/j.jnoncrysol.2006.12.023

[10] L.C. Prasad, R.N. Singh, A quasi-lattice model for the thermodynamic properties of au-zn liquid alloys, Phys. Chem. Liq. 22 (1990) 1. https://doi.org/10.1080/00319109008036406

[11] L.C. Prasad, R.N. Singh, V.N. Singh, S.K. Chatterjee, Compound formation in Sn-based liquid alloys, Phys. B Phys. Condens. Matter. 215 (1995) 225.

https://doi.org/10.1016/0921-4526(95)00393-N

[12] R.N. Singh, A.B. Bhatia, Flory' $s$ formula for the entropy of mixing of NaCs alloy, J. Phys. F: Met. Phys. 14 (1984) 2309. https://doi.org/10.1088/0305-4608/14/10/009

[13] S.K. Yadav, S. Lamichhane, L.N. Jha, N.P. Adhikari, D. Adhikari, Mixing behaviour of Ni-Al melt at 1873 K, Phys. Chem. Liq. 54 (2016) 370. https://doi.org/10.1080/00319104.2015.1095640

[14] S.K. Yadav, U. Mehta, R.K. Gohivar, A. Dhungana, R.P. Koirala, D. Adhikari, Reassessments of thermo-physical properties of SiTi melt at different temperatures, BIBECHANA 17 (2020) 146. https://doi.org/10.3126/bibechana.v17i0.26877

[15] O. Akinlade, R.N. Singh, Bulk and surface properties of liquid In-Cu alloys, J. Alloys Compd. 333 (2002) 84.

https://doi.org/10.1016/S0925-8388(01)01733-9
[16] B.C. Anusionwu, G.A. Adebayo, Quasi-chemical studies of ordering in the $\mathrm{Cu}-\mathrm{Zr}$ and $\mathrm{Cu}-\mathrm{Si}$ melts, J. Alloy. Compd. 329 (2001) 162. https://doi.org/10.1016/S0925-8388(01)01572-9

[17] O.E. Awe, Thermodynamic investigation of thermophysical properties of thallium-based liquid alloys, Phys. Chem. Liq. 57 (2019) 296. https://doi.org/10.1080/00319104.2018.1443453

[18] O.E. Awe, O. Akinlade, L.A. Hussain, Thermodynamic properties of liquid $\mathrm{Te}-\mathrm{Ga}$ and Te-Tl alloys, J. Alloys Compd. 361 (2003) 227. https://doi.org/10.1016/S0925-8388(03)00451-1

[19] A.B. Bhatia, W.H. Hargrove, D.E. Thornton, Concentration fluctuations and partial structure factors of compound-forming binary molten alloys, Phys. Rev. B 9 (1974) 435. https://doi.org/10.1103/PhysRevB.9.435

[20] A.B. Bhatia, R.N. Singh, A Quasi-lattice Theory for Compound Forming Molten Alloys, Phys. Chem. Liq. 13 (1984) 177. https://doi.org/10.1080/00319108608078511

[21] I. Koirala, I.S. Jha, B.P. Singh, Theoretical investigation on ordering nature of Cd-Bi alloys in the molten dtatemolten state, BIBECHANA. 11 (2014) 70.

https://doi.org/10.3126/bibechana.v11i0.10382

[22] I. Koirala, B.P. Singh, I.S. Jha, Theoretical assessment on segregating nature of liquid $\mathrm{In}-\mathrm{Tl}$ alloys, J. Non. Cryst. Solids 398 (2014) 26. https://doi.org/10.1016/j.jnoncrysol.2014.04.018

[23] A.B. Bhatia, W.H. Hargrove, Concentration fluctuations and thermodynamic properties of some compound forming binary molten systems, Phys. Rev. B 10 (1974) 3186. https://doi.org/10.1103/PhysRevB.10.3186

[24] R. Hultgren, P.D. Desai, D.T. Hawkins, M. Gleiser, K.K. Kelley, Selected Values of the Thermodynamic Properties of Binary Alloys., American Society for Metals, Metal Park, Ohio, (1973).

[25] E.A. Guggenheim, Mixtures, Oxford University Press, London (1952).

[26] H.C. Longuet-Higgins, The statistical thermodynamics of multicomponent systems, Proc. R. Soc. London. Ser. A. Math. Phys. Sci. 205 (1951) 247. https://doi.org/10.1098/rspa.1951.0028

[27] A.B. Bhatia, D.E. Thornton, Structural aspects of the electrical resistivity of binary alloys, Phys. Rev. B 2 (1970) 3004. 
https://doi.org/10.1103/PhysRevB.2.3004

[28] B.E. Warren, X-ray Diffraction, Dover Publication, New York, 1990.

[29] J.M. Cowley, An approximate theory of order in alloys, Phys. Rev. $77 \quad$ (1950) 669. https://doi.org/10.1103/PhysRev.77.669

[30] L.S. Darken, R.W. Gurry, Physical Chemistry of Metals, McGraw Hill, New York (1953).

[31] E.A. Moelwyn-Hughes, Physical Chemistry, Second, Pergamon, Oxford (1964).

[32] E.A. Brandes, G.B. Brook, Smithells Metals Reference Book, Seventh, Butterw orthHeinemann Linacre House, Jordan Hill, Oxford, 1992.

https://doi.org/10.1016/B978-075067509-3/50014-2
[33] J.A.V. Butler, The Thermodynamics of the Surfaces of Solutions, R. Soc. A. (1932) 348. https://doi.org/10.1098/rspa.1983.0054

[34] L.C. Prasad, R.N. Singh, V.N. Singh, G.P. Singh, Correlation between Bulk and Surface Properties of AgSn Liquid Alloys, J. Phys. Chem. B 102 (1998) 921. https://doi.org/10.1021/jp9710421

[35] L.C. Prasad, R.N. Singh, Surface segrgation and concentration fluctuation at the liquid-vapor interface of molten $\mathrm{Cu}-\mathrm{Ni}$ alloys, Phys. Rev. B 44 (1991) 768.

https://doi.org/10.1103/PhysRevB.44.13768 